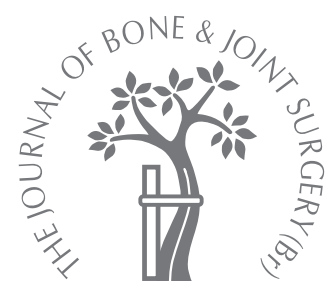

\title{
Grafting with hydroxyapatite granules for defects of acetabular bone at revision total hip replacement
}

\author{
A MINIMUM TEN-YEAR FOLLOW-UP
}

T. Sakai, K. Ohzono, T. Nishii, H. Miki, M. Takao, N. Sugano

\section{From Osaka} University Graduate School of Medicine, Suita, Japan

\begin{abstract}
The long-term results of grafting with hydroxyapatite granules for acetabular deficiency in revision total hip replacement are not well known. We have evaluated the results of revision using a modular cup with hydroxyapatite grafting for Paprosky type 2 and 3 acetabular defects at a minimum of ten years' follow-up. We retrospectively reviewed 49 acetabular revisions at a mean of 135 months (120 to 178). There was one type 2B, ten 2C, 28 3A and ten $3 \mathrm{~B}$ hips. With loosening as the endpoint, the survival rate was $74.2 \%(95 \%$ confidence interval 58.3 to 90.1$)$. Radiologically, four of the type 3A hips (14\%) and six of the type 3B hips $(60 \%)$ showed aseptic loosening with collapse of the hydroxyapatite layer, whereas no loosening occurred in type 2 hips. There was consolidation of the hydroxyapatite layer in 33 hips $(66 \%)$. Loosening was detected in nine of 29 hips $(31 \%)$ without cement and in one of 20 hips $(5 \%)$ with cement ( $p=0.03$, Fisher's exact probability test). The linear wear and annual wear rate did not correlate with loosening.
\end{abstract}

These results suggest that the long-term results of hydroxyapatite grafting with cement for type 2 and $3 A$ hips are encouraging.

\footnotetext{
- T. Sakai, MD, PhD, Assistant Professor

= M. Takao, MD, PhD, Assistant Professor

Department of Orthopaedic Surgery

Nishii, MD, PhD, Associate

Professor

N. Sugano, MD, PhD,

Professor

Department of Orthopaedic

Medical Engineering

Osaka University Graduate

School of Medicine, 2-2

Yamadaoka, 565-0871, Suita,

Japan.

K. Ohzono, MD, PhD, Vice President

Department of Orthopaedic Surgery

Kansai Rosai Hospital, 3-1-69,

Inabasou, 565-8511 Amagasaki,

Japan.

H. Miki, MD, PhD,

Orthopaedic Surgeon

Department of Orthopaedic

Surgery

Osaka National Hospital, 2-1-14

Hoenzaka, Chuo-ku, 540-0006,

Osaka, Japan.

Correspondence should be sent

to $\mathrm{Dr}$ T. Sakai; e-mail:

tsakai-osk@umin.ac.jp

(C)2010 British Editorial Society of Bone and Joint Surgery doi:10.1302/0301-620X.92B9. $24555 \$ 2.00$

$J$ Bone Joint Surg [Br] 2010;92-B:1215-21. Received 11 March 2010; Accepted after revision 15 April 2010
}

The lack of acetabular bone due to osteolysis, infection or aseptic loosening can cause considerable problems when revising a total hip replacement (THR). ${ }^{1-12}$ A number of different types of bone and bone substitute have been used to graft the defect including morsellised ${ }^{1-6}$ and massive allografts, ${ }^{5,7}$ and hydroxyapatite granules. ${ }^{8-10}$ Sintered hydroxyapatite granules are not resorbable ${ }^{13}$ and bind to bone physicochemically. ${ }^{14}$ They have been shown to give good results in revision THR when followed for up to ten years. ${ }^{8-10}$ However, the fate of the granules in revisions after more than ten years is unknown.

For revision of the acetabulum with deficiency of bone stock we use a large amount $(>10 \mathrm{~g})$ of hydroxyapatite granules and a modular reconstruction component. This study describes the clinical and radiological results of this method with a minimum followup of ten years.

\section{Patients and Methods}

Between January 1993 and August 1999, we revised 65 hips in 60 patients using a modular acetabular reconstruction component (ModuRec system, Zimmer, Warsaw, Indiana) (Fig. 1) and at least $10 \mathrm{~g}$ of hydroxyapatite granules. Of these, nine patients (ten hips) died within ten years from unrelated causes, and six (six hips) were lost to follow-up. Their clinical and radiological results at the last recorded follow-up did not show loosening. Thus, 49 hips in 45 patients were available for follow-up at a mean of 135 months (120 to 178). There were 39 women and six men, with a mean age at revision of 66 years (38 to 79). Their mean height was $149 \mathrm{~cm}$ (138 to 167), and mean weight $54.3 \mathrm{~kg}$ (40 to 70 ), giving a mean body mass index (BMI) of 24.4 (15.4 to 34.1). The reasons for revision were aseptic loosening of the component in 34 hips, aseptic loosening of a bipolar endoprosthesis in seven, and septic loosening of a THR or bipolar endoprosthesis in eight. The cumulative number of operations prior to the index acetabular revision was one in 29 hips, two in 14 hips, and three in six hips.

The classification system of Paprosky, Perona and Lawrence ${ }^{15}$ was used to evaluate the severity of the acetabular defect. One hip had a type $2 \mathrm{~B}$ acetabulum ( $>2 \mathrm{~cm}$ superior migration), ten had a type $2 \mathrm{C}$ (medial wall defect), 28 had a type $3 \mathrm{~A}(30 \%$ to $60 \%$ rim defect) and ten had a type 3B (>60\% rim defect).

The modular reconstructive component consisted of a flanged metal socket, an iliac lag screw and an ischial peg. It was made of titanium alloy (Ti-6A1-4V) and had a corundum-blasted surface finish. A conventional, gamma-sterilised ultra-high molecular weight 


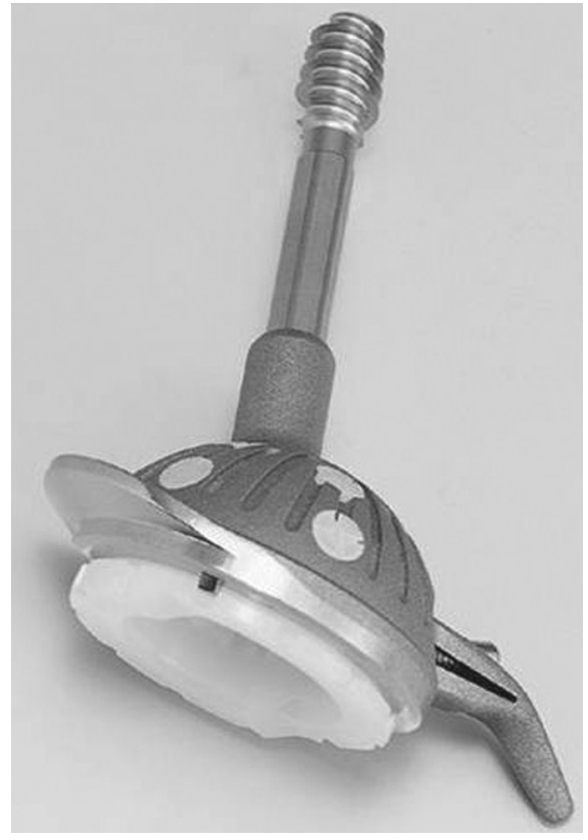

Fig. 1

The modular reconstructive cup (ModuRec system, Zimmer, Warsaw, Indiana).

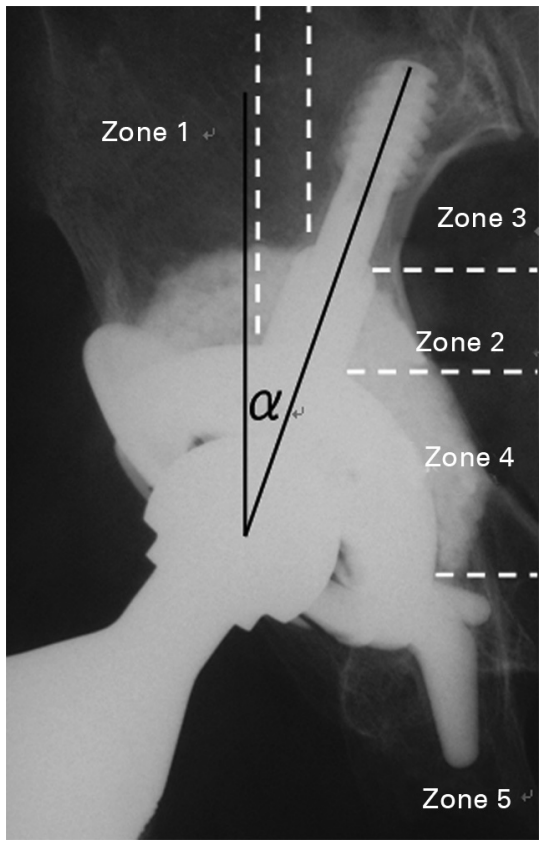

Fig. 2

The angle of the iliac lag screw and the five radiological zones. polyethylene (UHMWPE) liner was used with either a neutral or an elevated rim.

Through a posterolateral approach, the loose components and fibrous membrane were removed to expose the host bone. A guide wire was passed into the posterior column of the iliac bone using a jig without an image intensifier, and an iliac lag screw of appropriate length was inserted into the posterior column beside the sciatic notch. This bone is usually intact even in cases of severe acetabular deficiency, except in those with pelvic discontinuity.

The entire bone defect was then densely packed with hydroxyapatite granules and impacted with a trial component. The mean weight of granules (Bonfil, Mitsubishi Material, Tokyo, Japan or Boneceram P, Orimpus, Tokyo, Japan) used was $25 \mathrm{~g}$ (10 to 100). These were a mixture of small $(1.0 \mathrm{~mm}$ to $2.8 \mathrm{~mm})$ and larger $(2.8 \mathrm{~mm}$ to $5.0 \mathrm{~mm})$ diameter. Bonfil granules were used in 39 hips, and had a pore diameter of $90 \mu \mathrm{m}$ to $200 \mu \mathrm{m}$, a porosity rate of $60 \%$ and a mean compressive strength of $15 \mathrm{MPa}$. Boneceram $\mathrm{P}$ granules were used in ten hips, having a pore diameter of $50 \mu \mathrm{m}$ to $300 \mu \mathrm{m}$, and a porosity rate of $35 \%$ to $48 \%$, and a mean compressive strength of $35 \mathrm{MPa}$.

Next, a flanged metal socket was connected to the lag screw and impacted. The modular component was then located at the level of the original centre of the hip or as much as possible. An ischial peg was inserted and fixed through the window of the flanged metal socket. This socket has eight holes, through which additional bone and/ or further hydroxyapatite granules or screws can be introduced. Of the 49 hips, 29 components were fixed without cement and 20 with cement. Bone cement was used for the space occupying the non-weight-bearing part of the ischial bone and/or at the interface between the metal socket and the layer of hydroxyapatite when there was only a small contact area between the socket and the host bone. We did not use cement at the contact area between the host bone and the surface of the metal socket. No plate or fibular graft was used to reconstruct a rim defect.

At the index operation the femoral side was not revised in ten hips. The other 39 femoral components were revised, 31 to a cementless stem and eight to a cemented stem. A $28 \mathrm{~mm}$ alumina modular head (Biolox, Ceram Tec, Plochingen, Germany) was used in 14 hips, a $26 \mathrm{~mm}$ cobaltchrome head in 29 and a $28 \mathrm{~mm}$ cobalt-chrome head in four. The other two hips had monobloc heads, one was a Charnley stem with a $22 \mathrm{~mm}$ head and the other a stainless steel stem (SOM, Mizuho Co, Tokyo, Japan) with a $28 \mathrm{~mm}$ stainless steel head.

All patients received prophylactic intravenous antibiotics: $2 \mathrm{~g}$ of a second-generation cephalosporin were given at the time of anaesthesia, and then a further $2 \mathrm{~g}$ every 12 hours for one week. Patients without complications were allowed partial weight-bearing at three to six weeks, and full weight-bearing at six to 12 weeks after operation. Anticoagulants were not given: elastic stockings were used for the first two weeks.

Kaplan-Meier survival analysis was performed with two endpoints: radiological evidence of aseptic loosening and revision for any reason. The $95 \%$ confidence interval (CI) was also calculated. 


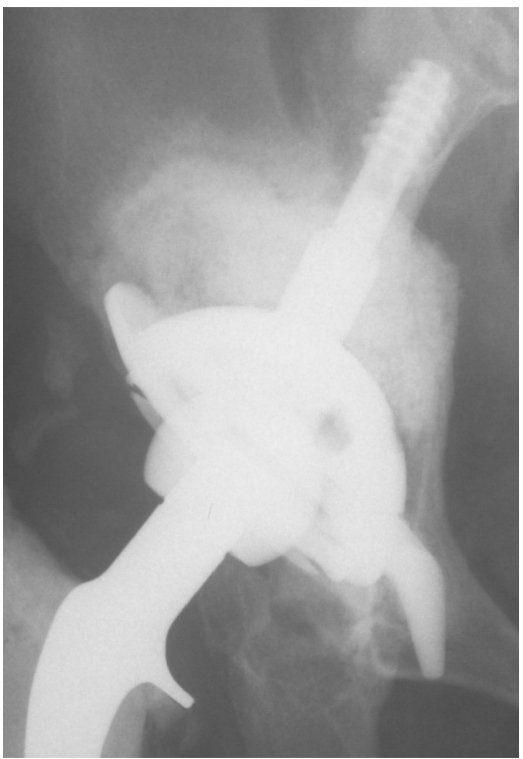

Fig. 3a

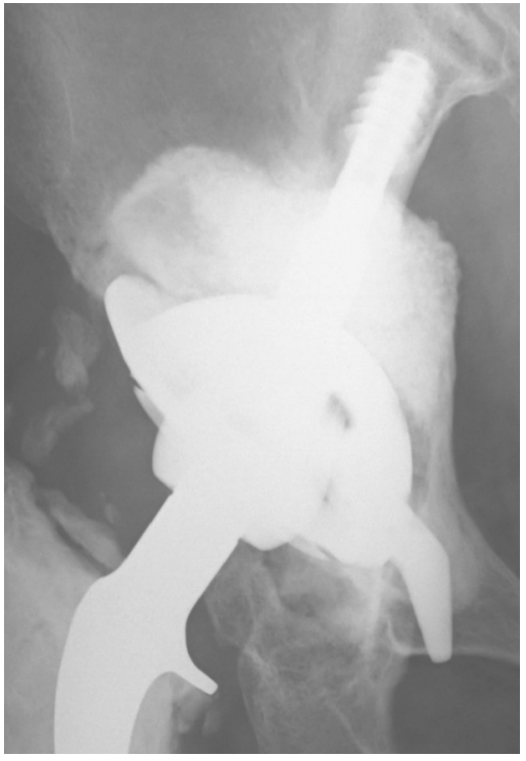

Fig. 3b

Radiograph taken a) immediately after acetabular revision for Paprosky type 3B hip in a 42-year-old woman. Hydroxyapatite granules (60 g, Bonfil, Mitsubishi Material, Tokyo, Japan) were used without cement and b) after 13 years, the hydroxyapatite layer showed consolidation without loosening.

The clinical and radiological data were evaluated by two independent observers (TS, NS) who had no prior knowledge of the results. The patients were assessed clinically before operation and at the latest follow-up using the Harris hip score (HHS) ${ }^{16}$ Anteroposterior (AP) and oblique radiographs were taken pre-operatively and at each follow-up visit. The location of the centre of the hip post-operatively was defined by the vertical distance from the teardrop line and the lateral distance from the vertical line through the symphysis pubis. ${ }^{17}$ We measured the angle of the iliac lag screw (the vertical axis was measured as from the vertical line to the teardrop line) in order to assess the position of the component (Fig. 2). Because the modular component has a unique shape, we defined five zones for the purpose of localising radiolucent lines as follows: zone 1 , the weight-bearing zone; zone 2 , around the sleeve; zone 3, around the iliac lag screw; zone 4, the medial wall; and zone 5, around the ischial peg (Fig. 2). Migration of the component, both horizontally and vertically, was measured using the method of Nunn et al. ${ }^{18}$ Acetabular loosening was confirmed if the sum of acetabular migration in the horizontal and vertical planes was $>5 \mathrm{~mm},{ }^{19}$ if the change in the orientation of the acetabular component was $>5^{\circ 20}$ if there was a progressive radiolucent line measuring $>1 \mathrm{~mm}$ in all zones as described by DeLee and Charnley. ${ }^{20}$ We also checked the consolidation of the hydroxyapatite, the interface between the bone and the hydroxyapatite granules and the change in the volume of this layer on the AP radiographs. ${ }^{8}$

Polyethylene wear of the acetabular liner was measured using Image.J ver.1.42q (National Institutes of Health, Bethesda, Maryland) on a Microsoft Windows (Microsoft, Redmond, Washington) computer. ${ }^{21}$ The two AP radiographs of the hips taken just after surgery and at the latest follow-up were digitised using an X-ray radiograph scanner. The diameter of the prosthetic femoral head was used to correct for magnification. A circle of known diameter was matched to the surface of the femoral head and another circle of known diameter was superimposed on the outer surface of the socket. By comparing the two the linear wear of the UHMWPE and the annual wear rate could be calculated. ${ }^{22}$ Statistical analysis. Comparison between the radiologically defined loosening hips and hips not loose was carried out using the Mann-Whitney $U$ test, the chi-squared test and Fisher's exact probability test. A p-value $<0.05$ was considered significant.

\section{Results}

At a mean of 135 months (120 to 178 ) post-operatively, Kaplan-Meier survival analysis gave a $74.2 \%$ probability (95\% CI 58.3 to 90.1 ) of retaining the modular component when radiological evidence of aseptic loosening was taken as the endpoint. For Paprosky type 2 and $3 \mathrm{~A}$ hips, the probability was $88.9 \%$ ( $95 \%$ CI 78.5 to 99.3 ). When revision for any reason was taken as the endpoint the probability was $66 \%$ (95\% CI 47.2 to 84.8 ).

The mean pain element of the HHS improved from 13.7 ( 0 to 30 ) to 33.9 points (20 to 44 ), and the mean total HHS from 41 (11 to 67 ) to 71 points ( 47 to 88 ).

There were two late infections $(4 \%)$, seven dislocations $(14 \%)$ and two breakages of the polyethylene liner 13 years post-operatively $(4 \%)$. There was no breakage of the flanged component or the iliac lag screw.

A total of 39 hips $(80 \%)$ showed no radiological evidence of aseptic loosening (Fig. 3), but ten hips (20\%) 


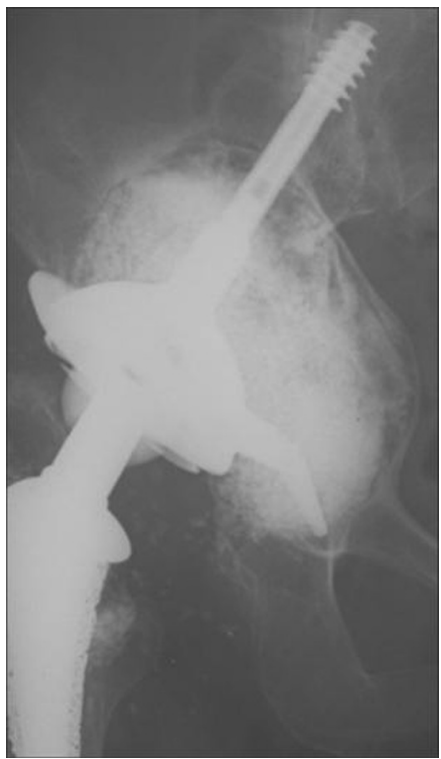

Fig. 4a

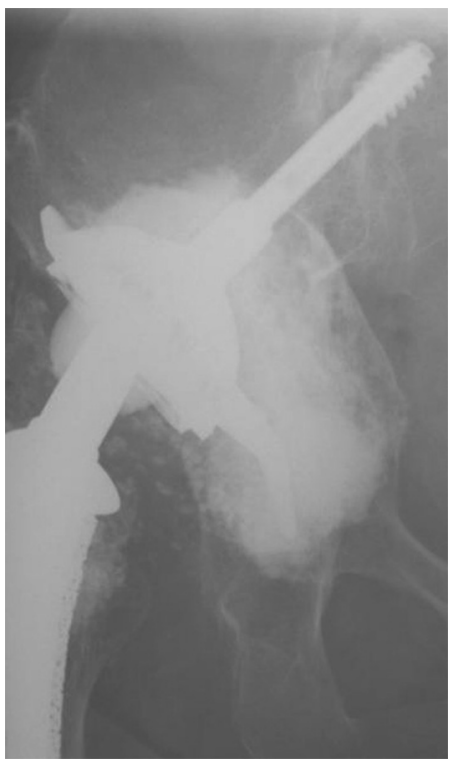

Fig. 4b

Radiograph taken a) immediately after acetabular revision for Paprosky type 3B hip in a 65-year-old woman. Hydroxyapatite granules $(100 \mathrm{~g}$, Boneceram P, Orimpus, Tokyo, Japan were used without cement and b) after 15 years, the hydroxyapatite layer had collapsed at the weight-bearing area, with varus migration.

became loose, with progressive migration and collapse of the hydroxyapatite layer in the weight-bearing area (Fig. 4). The hips with the most severe bone deficiency tended to loosen: four of 28 type $3 \mathrm{~A}$ hips $(14 \%)$ and six of ten type 3B hips $(60 \%)$ showed radiological evidence of loosening, compared to none of the 11 type 2 hips.
Regarding the location of the centre of the hip, the mean vertical distance from the teardrop line was $25.7 \mathrm{~mm}$ (12.5 to 37.8), whereas the mean lateral distance from the vertical line through the symphysis pubis was $86.7 \mathrm{~mm}$ (73.3 to 100.1). The mean angle of the iliac lag screw was $29.8^{\circ}\left(7^{\circ}\right.$ to $\left.52^{\circ}\right)$. A radiolucent line around the modular component was seen in eight hips $(16 \%)$ in zone 1,25 hips $(51 \%)$ in zone 2,26 hips $(53 \%)$ in zone 3 , seven hips (14\%) in zone 4 , and nine hips $(18 \%)$ in zone 5 .

Consolidation of the layer of hydroxyapatite granules was seen in 33 hips (67\%) (Fig. 3). Radiolucent lines between this layer and the host bone were seen in 11 hips $(22 \%)$. A reduction in the volume of the layer was seen in 13 hips (26\%).

The mean linear wear of UHMWPE at follow-up was $0.99 \mathrm{~mm}(0.07$ to 4.5$)$. The mean annual rate of wear was $0.12 \mathrm{~mm} /$ year $(0.01$ to 0.45$)$. Neither the linear wear nor the annual wear rate were found to correlate with loosening of the cup (Table I).

The size of the bone defect pre-operatively correlated strongly with loosening $(\mathrm{p}=0.004)$ (Table I). There were significant differences in the lateral position of the head centre $(\mathrm{p}=0.016)$, consolidation of the hydroxyapatite layer $(p=0.009)$, a radiolucent line between this layer and the host bone $(\mathrm{p}=0.004)$, reduction in volume $(\mathrm{p}=0.004)$ and use of cement $(\mathrm{p}=0.03)$ between the hips that loosened and those that did not. Loosening was seen in nine of 29 hips $(31 \%)$ without cement and in one of $20(5 \%)$ with cement.

Seven of ten hips that loosened had further revision surgery at a mean of 109 months (60 to 161). They were treated using a new modular reconstruction component and a metal plate and/or a fibular graft for the rim defect. At the second revision, three hips were Paprosky type 3B and the other four had pelvic discontinuity. Although hydroxyapatite granules did not show direct binding to the blasted surface of the loosened component, the granules themselves showed partial incorporation into the host bone. The interface between the host bone and the granules appeared solid. There was no evidence of loosening at a mean 87 months (30 to 120) after the second revision.

\section{Discussion}

Within ten years of acetabular revision, survival with additional surgery as the endpoint is about $90 \%$. This applies to the oblong cup, ${ }^{23,24}$ a custom-made cup, ${ }^{25}$ a tantalum cup, ${ }^{26}$ a trabecular metal cup, ${ }^{27}$ a cemented cup,, 3 metal cup with a structural bone graft, ${ }^{7}$ a polyethylene cup with a reinforcement ring, ${ }^{28-30}$ the Kerboull plate ${ }^{5,9,31}$ and the contour antiprotrusio cage. ${ }^{32}$ However, at longer than ten years after revision including the use of a modular cup, ${ }^{1}$ impacted bone grafting with a cemented cup, ${ }^{2}$ cementless jumbo cup, $, 33,34$ or a stemmed cup, ${ }^{35}$ the survival ranges from $43 \%$ to $100 \%$

We have shown similar results ( $88 \%$ survival) with a modular reconstruction cup and grafting with the hydroxyapatite granules and $3 \mathrm{~A}$ hips, ${ }^{1,2,33-35}$ although by 
Table I. Non-aseptic loosening hips and loosening hips

\begin{tabular}{|c|c|c|c|}
\hline Parameters & $\begin{array}{l}\text { Non-aseptic loosening } \\
\text { (39 hips) }\end{array}$ & $\begin{array}{l}\text { Aseptic loosening } \\
\text { (ten hips) }\end{array}$ & p-value \\
\hline Age in years (SD) & $65.8(9.8)$ & $64.3(5.5)$ & $0.275^{*}$ \\
\hline \multicolumn{4}{|l|}{ Gender } \\
\hline Men:women, hips & $5: 34$ & $3: 7$ & $0.333^{*}$ \\
\hline Height in cm (SD) & $148.3(6.6)$ & $153.7(4.7)$ & $0.275^{\dagger}$ \\
\hline Weight in $\mathrm{kg}$ (SD) & $53.4(7.9)$ & $58.0(7.2)$ & $0.061^{\dagger}$ \\
\hline Body mass index & $24.3(3.9)$ & $24.5(2.6)$ & $0.852^{\dagger}$ \\
\hline \multicolumn{4}{|l|}{ Operation times before the index revision (hips) } \\
\hline $1 / 2 / 3$ & $24 / 10 / 5$ & $5 / 4 / 1$ & $0.669^{\ddagger}$ \\
\hline The reason of the index revision ${ }^{\S}$ (hips) & $34 / 5$ & $7 / 3$ & $0.333^{*}$ \\
\hline \multicolumn{4}{|l|}{ Aseptic loosening/infection } \\
\hline \multicolumn{4}{|l|}{ Paprosky's classification ${ }^{\S}$ (hips) } \\
\hline Type $2 \mathrm{~B} / 2 \mathrm{C} / 3 \mathrm{~A} / 3 \mathrm{C}$ & $1 / 10 / 24 / 4$ & $0 / 0 / 4 / 6$ & $0.004^{\ddagger}$ \\
\hline \multicolumn{4}{|l|}{ Head centre (mm) (SD) } \\
\hline Vertical distance from the teardrop line & $25.2(6.9)$ & $27.7(6.9)$ & $0.309^{\dagger}$ \\
\hline Lateral distance from the vertical line through the sym & $85.5(6.1)$ & $91.1(5.6)$ & $0.016^{\dagger}$ \\
\hline Angle of the iliac lag screw $\left(^{\circ}\right)(\mathrm{SD})$ & $28.9(10.9)$ & $33.3(7.1)$ & $0.157^{\dagger}$ \\
\hline \multicolumn{4}{|l|}{ Hydroxyapatite (HA) granuleף (hips) } \\
\hline Bonfil/Boneceram P & $32 / 7$ & $7 / 3$ & $0.405^{*}$ \\
\hline Consolidation ( \pm ) & $30 / 9$ & $3 / 7$ & $0.009^{*}$ \\
\hline Radiolucent line between HA and host bone $( \pm)$ & $6 / 33$ & $5 / 5$ & $0.004^{*}$ \\
\hline Volume reduction on anteroposterior radiographs $( \pm)$ & $8 / 31$ & $6 / 4$ & $0.004^{*}$ \\
\hline Cement use $( \pm$, hips $)$ & $19 / 20$ & $1 / 9$ & $0.03^{*}$ \\
\hline \multicolumn{4}{|l|}{ Polyethylene wear } \\
\hline Linear wear $(\mathrm{mm})(\mathrm{SD})$ & $1.01(0.95)$ & $0.93(0.52)$ & $0.695^{\dagger}$ \\
\hline Annual linear wear rate (mm/year) (SD) & $0.12(0.13)$ & $0.13(0.09)$ & $0.484^{\dagger}$ \\
\hline \multicolumn{4}{|l|}{ * Fisher's exact probability test } \\
\hline \multicolumn{4}{|l|}{ † Mann-Whitney U test } \\
\hline \multicolumn{4}{|l|}{ ‡ chi-squared test } \\
\hline \multicolumn{4}{|c|}{$\S$ type 2: superior migration/medial wall defect; type 3A: $30 \%$ to $60 \%$ rim defect; type $3 \mathrm{~B}:>60 \%$ rim defect } \\
\hline \multicolumn{4}{|c|}{$\begin{array}{l}\text { T hydroxyapatite granules } 1.0 \mathrm{~mm} \text { to } 2.8 \mathrm{~mm} \text { and } 2.8 \mathrm{~mm} \text { to } 5.0 \mathrm{~mm} \text { in diameter were mixed. Bonfil and Boneceram } \mathrm{P} \text { granules had } \\
\text { a mean diameter of porosity of } 90 \mu \mathrm{m} \text { to } 200 \mu \mathrm{m} \text { amd } 50 \mu \mathrm{m} \text { to } 200 \mu \mathrm{m} \text {, with a porosity rate of } 60 \% \text { and } 35 \% \text { to } 48 \% \text {, and a mean } \\
\text { compressive strength of } 15 \mathrm{MPa} \text { and } 35 \mathrm{MPa} \text {, respectively }\end{array}$} \\
\hline
\end{tabular}

ten years $60 \%$ of Paprosky 3B hips showed signs of loosening. Schreurs et $\mathrm{al}^{2}$ recorded a $75 \%$ survival at 20 years using a cemented cup and impaction grafting with morsellised cancellous bone chips, $7 \mathrm{~mm}$ to $10 \mathrm{~mm}$ in size.

Hydroxyapatite is a useful bone substitute for acetabular reconstruction. Immunoreactivity can be ignored, no morphological change or decrease in volume occurs and it is minimally absorbed. Although some studies have reported the use of hydroxyapatite granules in acetabular revision, ${ }^{8-10}$ no study has reported the results ten or more years after surgery.

In our study, the granules were found not to have bound directly to the corundum-blasted surface of the loose modular component at further revision. It may therefore be better to carry out a cemented further revision, in order to bind the hydroxyapatite granules on to the surface of the acetabular component. ${ }^{8,9}$
The hydroxyapatite granules did not influence polyethylene wear. The mean linear wear $(0.99 \mathrm{~mm})$ and the annual rate of wear $(0.12 \mathrm{~mm} /$ year $)$ did not differ markedly from other studies, including those that used a combination of a polyethylene acetabular component and a $28 \mathrm{~mm}$ alumina ceramic head $(1.1 \mathrm{~mm}, 0.10 \mathrm{~mm} / \text { year })^{21}$ or those using a combination of a UHMWPE acetabular component and a $28 \mathrm{~mm}$ cobalt-chrome head $(0.85 \mathrm{~mm}$, $0.10 \mathrm{~mm} /$ year). ${ }^{22}$ Although severe osteolysis has been reported as a result of third-body wear from hydroxyapatite particles becoming detached from the coating of the acetabular component, ${ }^{36}$ we found no significant macroscopic UHMWPE wear due to hydroxyapatite granules from the grafted area.

The size and shape of the granules may influence the longevity of the hydroxyapatite layer and hence the 
acetabular component. Although two sizes of granule $(1.0 \mathrm{~mm}$ to $2.8 \mathrm{~mm}$ and $2.8 \mathrm{~mm}$ to $5.0 \mathrm{~mm}$ ) were mixed, and there were no differences in the two types of granule, a block or larger granules may be more useful to fill a bone defect. Kawanabe et $\mathrm{al}^{5}$ have reported that when using an allograft, a block gives a better result than a morsellised graft. The combination of hydroxyapatite granules and allograft or autograft bone may enhance osteoinduction.

The survival of a modular cup and hydroxyapatite depends on the type of bone defect in the acetabulum. It is important that the modular cup is in contact with host bone. For Paprosky type 3B cases, reconstruction of the acetabular rim using fibula or a plate was needed because a defect of $>60 \%$ of the acetabular rim cannot be reconstructed tightly using only hydroxyapatite granules. Poor results have been also reported with impaction allografting for severe acetabular bone deficiency. ${ }^{6}$ Van Haaren et $\mathrm{al}^{6}$ observed that 20 of their 71 revisions using impaction allograft bone needed further revision after a mean of 7.2 years; 14 of these 20 failures had an American Academy of Orthopaedic Surgeons classification type III or IV bone defect.

Jeffery et $\mathrm{al}^{1}$ reported that a modular component used for acetabular revision (Freeman) had a survival of $43 \%$ at 15 years in 21 hips. They also noted that breakage of the screw of the uncemented non-porous metal-backed prosthesis with augmentation occurred over ten years because the impacted allograft failed to incorporate and gave insufficient stability. In our study there was no breakage of the iliac lag screw. When the hydroxyapatite granule layer collapsed, the lag screw did not break because of its size, but migrated into a varus position until the flanged cup came into contact with the host bone.

One limitation of this study is the comparatively light weight of the patients, a mean $54.3 \mathrm{~kg}$ (40 to 70). This may not translate to a typical Western population. The mean BMI was $24.4 \mathrm{~kg}$ (15.4 to 34.1) and further study of the use of this modular component and hydroxyapatite granules is needed for heavier patients.

Acetabular revision using a large volume of hydroxyapatite granules and a modular cup with cement for Paprosky type 2 and 3A hips gives comparable clinical and radiological results to other methods for more than ten years. ${ }^{1,2,33-35}$ Although type $3 \mathrm{~B}$ cases fared poorly if only hydroxyapatite granules were used, the rest of the revision cases, who were evaluated as type $3 \mathrm{~B}$ and/or pelvic discontinuity, and were treated with a metal plate and/or fibular graft for the rim defect, had not loosened at a mean of 87 months after additional revision. Therefore, Paprosky type 3B hips need revision with both hydroxyapatite granules and reconstruction of the acetabular rim.

We thank Dr S. Nishihara, Dr M. Aihara, Dr S. B. Lee and Professor H. Yoshikawa for technical support.

No benefits in any form have been received or will be received from a commercial party related directly or indirectly to the subject of this article.

\section{References}

1. Jeffery M, Scott G, Freeman M. Failure of an uncemented non-porous metalbacked prosthesis with augmentation using impacted allograft for acetabular revision: 12- to 17-year results. J Bone Joint Surg [Br] 2003;85-B:182-6.

2. Schreurs BW, Keurentjes JC, Gardeniers JW, et al. Acetabular revision with impacted morsellised cancellous bone grafting and a cemented component: a 20- to 25-year follow-up. J Bone Joint Surg [Br] 2009;91-B:1148-53.

3. Wang JW, Fong CY, Su YS, Yu HN. Acetabular revision with morsellised allogenic bone graft and a cemented metal-backed component. J Bone Joint Surg [Br] 2006;88-B:586-91.

4. Comba F, Buttaro M, Pusso R, Piccaluga F. Acetabular reconstruction with impacted bone allografts and cemented acetabular components: a 2- to 13-year follow-up study of 142 aseptic revisions. J Bone Joint Surg [Br] 2006;88-B:865-9.

5. Kawanabe K, Akiyama H, Onishi E, Nakamura T. Revision total hip replacement using the Kerboull acetabular reinforcement device with morsellised or bulk graft: results at a mean follow-up of 8.7 years. J Bone Joint Surg [Br]2007;89-B:2631

6. van Haaren EH, Heyligers IC, Alexander FG, Wuisman PI. High rate of failure of impaction grafting in large acetabular defects. J Bone Joint Surg [Br] 2007;89B:296-300

7. Sporer SM, O'Rourke M, Chong P, Paprosky WG. The use of structural distal femoral allografts for acetabular reconstruction: average ten-year follow-up. $J$ Bone Joint Surg [Am] 2005;87-A:760-5

8. Oonishi H, Iwaki Y, Kin N, et al. Hydroxyapatite in revision of total hip replacements with massive acetabular defects: 4- to 10 -year clinical results. J Bone Joint Surg $[\mathrm{Br}]$ 1997;79-B:87-92

9. Tanaka C, Shikata J, Ikenaga M, Takahashi M. Acetabular reconstruction using a Kerboull-type acetabular reinforcement device and hydroxyapatite granules: a 3- to 8-year follow-up study. J Arthroplasty 2003;18:719-25.

10. Sudo A, Hasegawa M, Fukuda A, et al. Acetabular reconstruction using a cementless cup and hydroxyapatite granules: 3- to 8-year clinical results. J Arthroplasty 2007;22:828-32

11. Kosashvili Y, Backstein D, Safir O, Lakstein D, Gross AE. Acetabular revision using anti-protrusion (ilio-ischial) cage and trabecular metal acetabular component for severe acetabular bone loss associated with pelvic discontinuity. J Bone Joint Surg [Br] 2009;91-B:870-6.

12. Lingaraj K, Teo YH, Bergman $\mathbf{N}$. The management of severe acetabular bone defects in revision hip arthroplasty using modular porous metal components. J Bone Joint Surg [Br] 2009;91-B:1555-60.

13. Hoogendoorn HA, Renooij W, Akkermans LMA, Visser M, Wittebol P. Longterm study of large ceramic implants (porous hydroxyapatite) in dog femora. Clin Orthop 1984;187:281-8.

14. Jarcho M, Kay JF, Gumaer KI, Doremus RH, Drobeck HP. Tissue, cellular and subcellular events at a bone-ceramic hydroxyapatite interfaces. J Bioeng 1977;1:79-92

15. Paprosky WG, Perona PG, Lawrence JM. Acetabular defect classification and surgical reconstruction in revision arthroplasty: a 6 -year follow-up evaluation. $J$ Arthroscopy 1994;9:33-44.

16. Harris WH. Traumatic arthritis of the hip after dislocation and acetabular fractures: treatment by mold arthroplasty: an end-result study using a new method of result evaluation. J Bone Joint Surg [Am] 1969;51-A:737-55.

17. Asayama I, Chamnongkich S, Simpson KJ, Kinsey TL, Mahoney OM. Reconstructed hip joint position and abductor muscle strength after total hip arthroplasty. $J$ Arthroplasty 2005;20:414-20.

18. Nunn D, Freeman MA, Hill PF, Evans SJ. The measurement of migration of the acetabular component of hip prosthese. J Bone Joint Surg [Br] 1989;71-B:629-31.

19. Ochs BG, Schmid U, Rieth J, et al. Acetabular bone reconstruction in revision arthroplasty: a comparison of freeze-dried, irradiated and chemically-treated allograft vitalised with autologous marrow versus frozen non-irradiated allograft. $J$ Bone Joint Surg [Br] 2008;90-B:1164-71.

20. DeLee JG, Charnley J. Radiographic demarcation of cemented sockets in total hip replacement. Clin Orthop 1976;121:20-32.

21. Sugano N, Nishiii T, Nakata K, Masuhara K, Takaoka K. Polyethylene sockets and alumina ceramic heads in cemented total hip arthroplasty: a ten-year study. $J$ Bone Joint Surg [Br] 1995;77-B:548-56.

22. Livermore J, Ilstrup D, Morrey B. Effect of femoral head size on wear of the polyethylene acetabular component. J Bone Joint Surg [Am] 1990;72-A:518-28.

23. Surace MF, Zatti G, De Pietri M, Cherubino P. Acetabular revision surgery with the LOR cup: three to 8 years' follow-up. J Arthroplasty 2006;21:114-21.

24. Landor I, Vavrik P, Jahoda D, et al. The Long Oblique Revision component in revision arthroplasty of the hip. J Bone Joint Surg [Br] 2009;91-B:24-30.

25. Holt GE, Dennis DA. Use of custom triflanged acetabular components in revision total hip arthroplasty. Clin Orthop 2004;429:209-14. 
26. Ungar AS, Lewis RJ, Gruen T. Evaluation of a porous tantalum uncemented acetabular cup in revision total hip arthroplasty: clinical and radiological results of 60 hips. J Arthroplasty 2005;20:1002-9.

27. Sporer SM, Paprosky WG. Acetabular revision using a trabecular metal acetabular component for severe acetabular bone loss associated with a pelvic discontinuity. J Arthroplasty 2006;21(Suppl):87-90.

28. Winter E, Piert M, Volkmann R, et al. Allogeneic cancellous bone graft and a Burch-Schneider ring for acetabular reconstruction in revision hip arthroplasty. $J$ Bone Joint Surg [Am] 2001;83-A:862-7.

29. Gerber A, Pisan M, Zurakowski D, Isler B. Ganz reinforcement ring for reconstruction of acetabular defects in revision total hip arthroplasty. J Bone Joint Surg [Am] 2003;85-A:2358-64.

30. Carroll FA, Hoad-Reddick DA, Kerry RM, Stockley I. The survival of support rings in complex acetabular revision surgery. J Bone Joint Surg [Br] 2008;90B:574-8.
31. Kerboull M, Hamadouche M, Kerboull L. The Kerboull acetabular reinforcement device in major acetabular reconstructions. Clin Orthop 2000;378:155-68.

32. Bostrom MP, Lehman AP, Buly RL, Lyman S, Nestor BJ. Acetabular revision with the Contour antiprotrusio cage: 2- to 5-year follow-up. Clin Orthop 2006;453:188-94.

33. Hallstrom BR, Golladay GJ, Vittetoe DA, Harris WH. Cementless acetabular revision with the Harris-Galante porous prosthesis: results after a minimum of ten years of follow-up. J Bone Joint Surg [Am] 2004;86-A:1007-11.

34. Hendricks KJ, Harris WH. Revision of failed acetabular components with use of socalled jumbo noncemented components: a concise followup of a previous report. $J$ Bone Joint Surg [Am]2006;88-A:559-63.

35. Badhe NP, Howard PW. A stemmed acetabular component in the management of severe acetabular deficiency. J Bone Joint Surg [Br]2005;87-B:1611-16.

36. Morscher EW, Hefti A, Aebi U. Severe osteolysis after third-body wear due to hydroxyapatite particles from acetabular cup coating. J Bone Joint Surg [Br] 1998;80B:267-72. 